\title{
Heterogeneous advanced photo- Fenton process using peroxymonosulfate and peroxydisulfate in presence of zero valent metallic iron: A comparative study with hydrogen peroxide photo-Fenton process
}

\author{
L. Gomathi Devi*, M. Srinivas, M.L. ArunaKumari \\ Department of Post Graduate Studies in Chemistry, Central College City Campus, Dr. Ambedkar Street, Bangalore University, Bangalore-560001, India
}

\section{A R T I C L E I N F O}

\section{Article history:}

Received 27 February 2016

Received in revised form 6 August 2016

Accepted 10 August 2016

\section{Keywords:}

Zero valent metallic iron

Oxone

Ammonium persulfate

Photo-Fenton process

Peroxymonosulfate

Peroxydisulfate

\begin{abstract}
A B S T R A C T
The present research work has demonstrated the use of zero valent metallic iron ( $\left.\mathrm{Fe}^{0}\right)$ in the photoFenton process under the UV illumination as a promising and novel technique. Oxidants like oxone a peroxymonosulfate (PMS) and ammonium persulfate a peroxydisulfate (PDS) were used in comparison with classical hydrogen peroxide (HP). PMS was found to be a better oxidant in comparison with $\mathrm{HP}$ and PDS at higher $\mathrm{pH}$ conditions especially in the $\mathrm{pH}$ range of 5-7. PMS acts as better oxidant with dipolar unsymmetrical structure, higher oxidation potential and its lower LUMO energy can easily accept electrons more readily compared to the other two oxidants. The degradation rate for various oxidation processes at $\mathrm{pH} 3$ shows the following decreasing order: $\mathrm{Fe}^{0} / \mathrm{PMS} / \mathrm{UV} \approx \mathrm{Fe}^{0} / \mathrm{HP} / \mathrm{UV}>\mathrm{Fe}^{0} / \mathrm{PDS} /$ $\mathrm{UV}>\mathrm{HP} / \mathrm{UV}>\mathrm{PDS} / \mathrm{UV}>\mathrm{PMS} / \mathrm{UV}>\mathrm{Fe}^{0} / \mathrm{PMS} /$ dark $>\mathrm{Fe}^{0} / \mathrm{HP} /$ dark $>\mathrm{Fe}^{0} / \mathrm{PDS} /$ dark $>\mathrm{Fe}^{0} / \mathrm{UV}>\mathrm{Fe}^{0} /$ dark. At $\mathrm{pH}$ 5 , PMS/UV and PDS/UV systems show similar efficiencies as $\mathrm{Fe}^{0} / \mathrm{PMS} / \mathrm{UV}$ and $\mathrm{Fe}^{0} / \mathrm{PDS} / \mathrm{UV}$ process, since most of the $\mathrm{Fe}^{0}$ surface is covered by the precipitates of hydroxide and oxyhydroxides. Though recycling capability of iron powder is almost comparable for first to fifth repetitions, $\mathrm{Fe}^{0}$ retains its recycling capability better in the presence of HP for the further runs rather than PDS and PMS.
\end{abstract}

(C) 2016 Elsevier Ltd. All rights reserved.

\section{Introduction}

Water pollution by the presence of toxic and non-biodegradable organic materials especially in parts per million ( $\mathrm{ppm}$ ) concentrations in drinking water brings about serious threat to the living species. The enormous diversity of pollutants with different chemical structure and composition excludes the possibility of using a universal treatment method and thus requires the development of special skilled treatment techniques to address the problem. Advanced oxidation processes (AOPs) such as $\mathrm{UV} / \mathrm{H}_{2} \mathrm{O}_{2}$, ozonation, photo Fenton, $\gamma$-radiolysis, sonolysis, electrochemical oxidation and semiconductor-mediated photocatalysis is extensively explored to mitigate a great variety of pollutants present in various environmental media. The advantage of these AOPs is that, it works at ambient temperature and pressure for the water treatment process which involves the generation of highly reactive free radicals in sufficient quantity for effective water purification

\footnotetext{
* Corresponding author.

E-mail address: gomatidevi_naik@yahoo.co.in (L.G. Devi).
}

$[1,2]$. Among the various AOP technologies, oxidation with the Fenton's reagent is proved as an effective and promising method for the destruction of a wide range of contaminants in wastewater as described in several research reviews [3-9].

The origin of Fenton process reported in 1894 shows the utility of ferrous ions as catalyst along with hydrogen peroxide for the oxidation of tartaric acid [10]. However, the positive role of hydroxyl free radicals in the Fenton oxidation reaction was confirmed much later $[11,12]$. The mechanism and kinetics of the Fenton reactions have been explored and studied by many researchers till date. The brief mechanism of classic homogeneous Fenton process involves the formation of hydroxyl and hydroperoxyl radicals as shown in Eqs. (1)-(5).

$$
\begin{aligned}
& \mathrm{Fe}^{2+}+\mathrm{H}_{2} \mathrm{O}_{2} \rightarrow \mathrm{Fe}^{3+}+\mathrm{OH}^{\bullet}+\mathrm{OH}^{-} \\
& \mathrm{Fe}^{3+}+\mathrm{H}_{2} \mathrm{O}_{2} \rightarrow \mathrm{Fe}^{2+}+{ }^{\circ} \mathrm{O}_{2} \mathrm{H}+\mathrm{H}^{+} \\
& \mathrm{Fe}^{2+}+\mathrm{OH}^{\circ} \rightarrow \mathrm{Fe}^{3+}+\mathrm{OH}^{-} \\
& \mathrm{OH}^{\circ}+\mathrm{H}_{2} \mathrm{O}_{2} \rightarrow{ }^{\circ} \mathrm{O}_{2} \mathrm{H}+\mathrm{H}_{2} \mathrm{O} \\
& \bullet \mathrm{O}_{2} \mathrm{H}+{ }^{\circ} \mathrm{O}_{2} \mathrm{H} \rightarrow \mathrm{H}_{2} \mathrm{O}_{2}+\mathrm{O}_{2}
\end{aligned}
$$




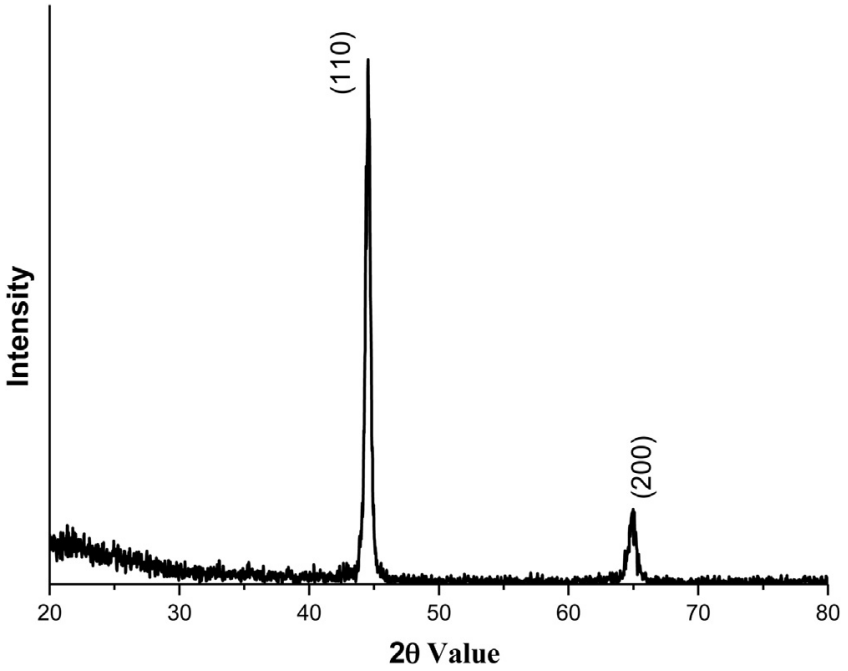

Fig. 1. X-Ray diffraction pattern of $\mathrm{Fe}^{0}$.

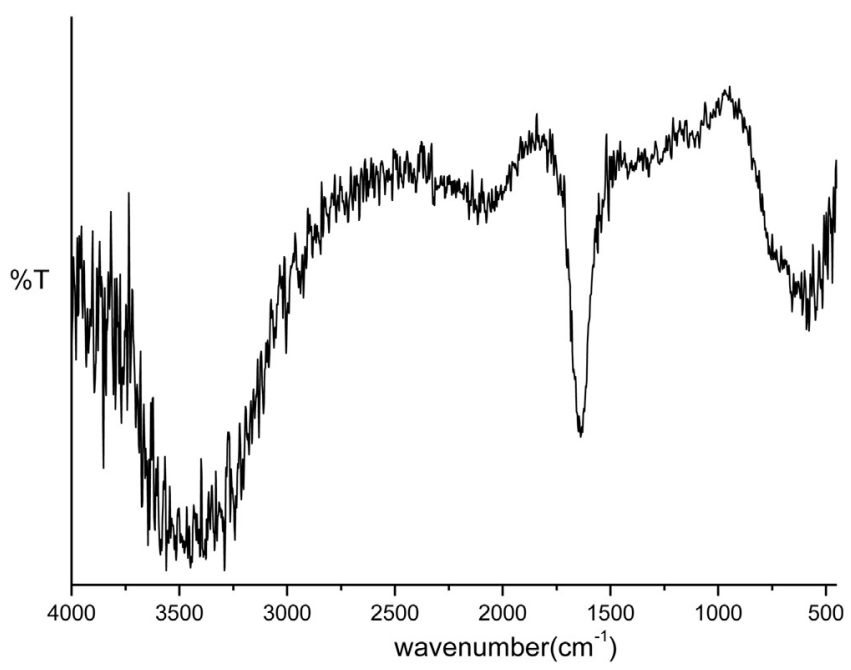

Fig. 2. FTIR spectra of $\mathrm{Fe}^{0}$.

However, there are some drawbacks and limitations in the classical homogeneous Fenton system like; (i) the excess ferric ions remaining in the treated wastewater requires an additional separation step for its removal, this complicates the overall process efficiency which makes it laborious and uneconomical. (ii) Classic Fenton's reagent work well only in $\mathrm{pH}$ range of 3-4, but at higher $\mathrm{pH}$, iron precipitates as hydroxide in the aqueous reaction medium. (iii) The cost of hydrogen peroxide (HP) is comparatively high for its application in wastewater treatment engineering and its long-term stability in the aqueous reaction medium is of further concern. Therefore, researchers have been actively involved in overcoming these problems. One of the efforts made in this regard is to use solid phase catalyst particles, which is termed as heterogeneous Fenton process with wide working $\mathrm{pH}$ range of $3-7$. The second effort is to develop Fenton process in combination with other AOP technologies such as photo-Fenton process, sonoFenton process, electro-Fenton and electro-photo Fenton process to enhance the rate of generation of hydroxyl radicals and thus reduce the excess consumption of oxidants like HP [13,14]. Among these AOP's the present research work mainly focuses on Heterogeneous photo-Fenton process [15-19]. To overcome the problem of removal of $\mathrm{Fe}^{2+} / \mathrm{Fe}^{3+}$ ions from the sludge, use of zero-valent iron $\left(\mathrm{Fe}^{0}\right)$ was largely proposed in recent years and the method has been

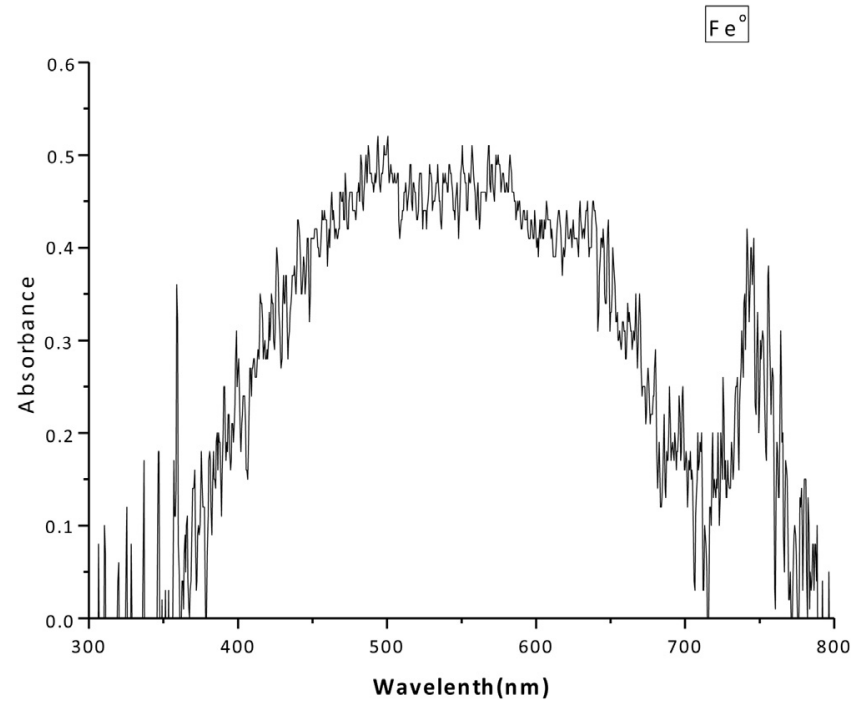

Fig. 3. UV-vis absorbance spectra of $\mathrm{Fe}^{0}$.

extensively applied and studied for its excellent ability to degrade the organic pollutants [20-27]. The standard reduction potential of elemental iron $\left(\mathrm{Fe}^{0}\right)$ to the dissolved ionic iron $\left(\mathrm{Fe}^{0} / \mathrm{Fe}^{2+}\right)$ is around $-0.440 \mathrm{~V}$ and this redox couple is actively involved in the in-situ remediation of contaminated groundwater $[21,22]$. Hence, the use of $\mathrm{Fe}^{0}$ nano powder as a source of $\mathrm{Fe}^{2+}$ ions for the catalytic decomposition of HP to produce reactive hydroxyl radicals is an alternative technique. Further addition of ammonium persulfate and oxone as oxidants instead of HP to generate sulfate free radicals in addition to hydroxyl radicals seems to be technique that is more advantageous. More precisely hydroxyl free radical based AOP in classical Fenton process is replaced by the generation of both sulfate and hydroxyl free radical based advanced/modified photo-Fenton AOP [28-32]. Persulfate salts are easy to store and transport, since it occurs as solid at ambient temperature and shows moderate stability in the subsurface environment, posses high water solubility and relatively low cost compared to $\mathrm{HP}[33,34]$. The added advantage of using persulfate as an oxidizing agent is, it reacts less readily with natural organic matters (NOMs) [35]. Oxone is a triple potassium salt containing $2 \mathrm{KHSO}_{5}{ }^{-} \mathrm{KHSO}_{4}{ }^{-} \mathrm{K}_{2} \mathrm{SO}_{4}$ components in which peroxymonosulfate $\left(\mathrm{HSO}^{-}{ }_{5}\right)$ ion is most active species. In recent years, peroxymonosulfate has been widely launched as an environmental friendly and adaptable oxidant in water treatment process [36]. Ammonium per sulfate containing peroxydisulfate(PDS) and oxone containing peroxymonosulfate (PMS) is used in this research study, which can produce simultaneously both hydroxyl and sulfate free radicals under UV irradiation. As reported in the literature, homogeneous Fenton process of the type UV/PMS/Fe ${ }^{2+}$ and $\mathrm{UV} / \mathrm{PDS} / \mathrm{Fe}^{2+}$ technologies are highly attractive because of their low operational costs and high organic pollutant removal efficiency [37-39]. The main aim of this study was to improve the above process and evaluate the effectiveness of sulfate free radical based AOPs mainly focusing on the metallic iron in $\mathrm{Fe}^{0} / \mathrm{PMS} / \mathrm{UV}$ and $\mathrm{Fe}^{0} / \mathrm{PDS} / \mathrm{UV}$ heterogeneous process in comparison with $\mathrm{Fe}^{0} / \mathrm{HP} / \mathrm{UV}$ process for the degradation of a model pollutant Methyl Violet (MV). Low concentration of iron was used in order to avoid the formation of iron oxide sludge thereby preventing the post treatment cost. Various reaction conditions like initial oxidant concentration, dosage of $\mathrm{Fe}^{0}$ catalyst and initial concentration of $\mathrm{MV}$ at different $\mathrm{pH}$ conditions were studied in detail. 


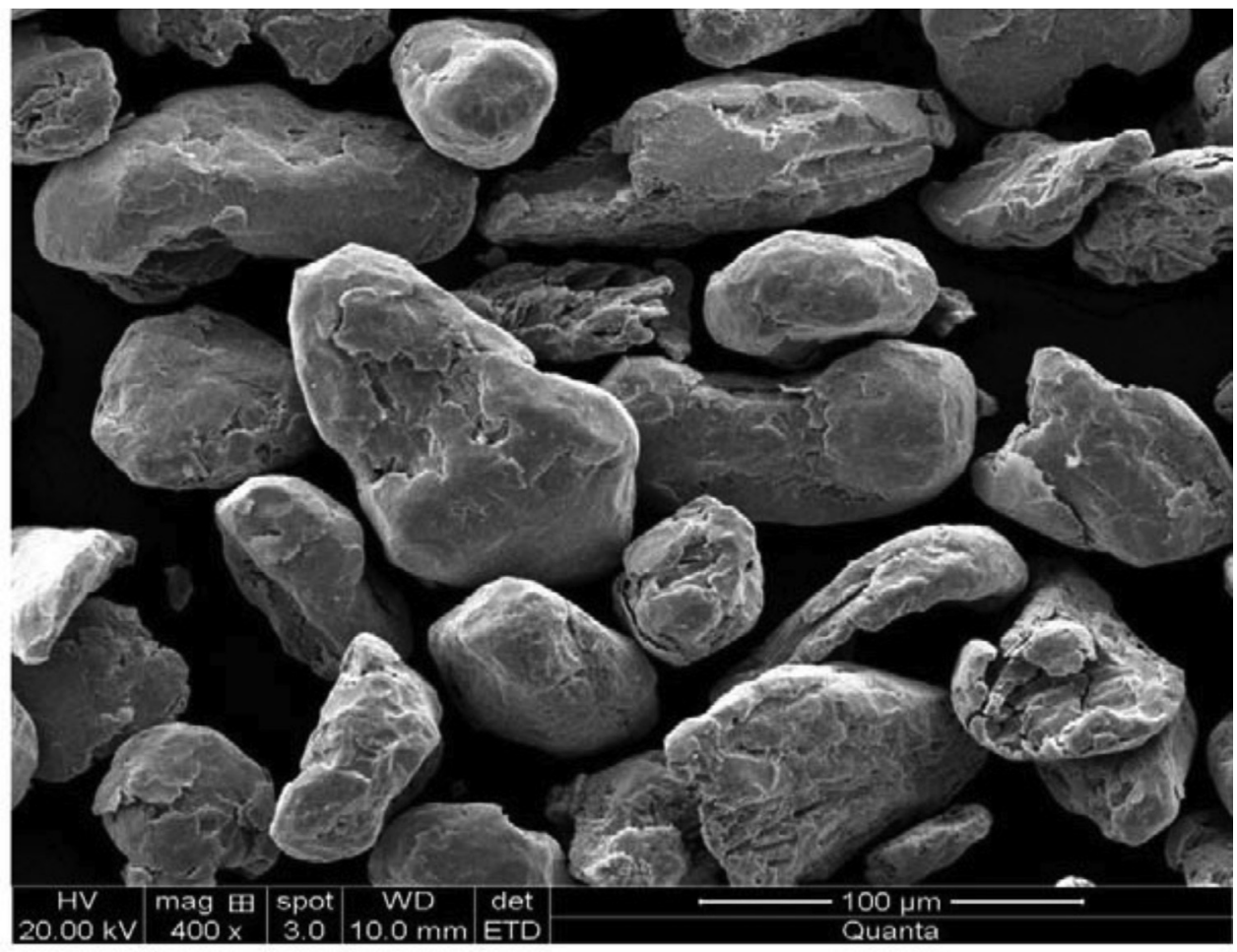

Fig. 4. SEM image of $\mathrm{Fe}^{0}$.

\section{Experimental}

\subsection{Materials and reagents}

Zero valent metallic Iron powder $\left(\mathrm{Fe}^{0}\right), 30 \% \mathrm{w} / \mathrm{v}$ hydrogen peroxide (HP) and ammonium per sulfate (PDS) $\left[\left(\mathrm{NH}_{4}\right)_{2} \mathrm{~S}_{2} \mathrm{O}_{8}\right]$ were supplied from Nice chemicals. The Methyl Violet (MV) dye was obtained from Sigma Aldrich. Oxone $\left(2 \mathrm{KHSO}^{5-} \mathrm{KHSO}^{4-} \mathrm{K}_{2} \mathrm{SO}_{4}\right)$ was obtained by Avra synthesis Pvt. Ltd. Sodium hydroxide ( $\mathrm{NaOH})$ and hydrochloric acid $(\mathrm{HCl})$ were from Sisco-chemical industries. All chemicals were analytic grade reagents and used without further purification. Double distilled water was used in all the experiments. The $\mathrm{pH}$ meter (Orion 920A pH meter) was calibrated with standard buffer solution before every measurement. The $\mathrm{pH}$ adjustments were done by either using $0.1 \mathrm{~N} \mathrm{NaOH}$ or $0.1 \mathrm{~N} \mathrm{HCl}$ solutions. The photo-Fenton processes were conducted at different $\mathrm{pH}$ conditions like $1,3,5,7$ and 9.

\subsection{Characterization techniques}

The powder X-ray diffraction (PXRD) patterns were obtained for the samples using Philips powder diffractrometer PW/1050/70/76. The diffraction patterns were recorded at room temperature using $\mathrm{Cu} \mathrm{K} \alpha$ radiation with $\mathrm{Ni}$ filter in $2 \theta$ range $20^{\circ}-80^{\circ}$ at a scan rate of $2^{\circ}$ per min. To study the light absorption characteristics of the prepared photocatalyst, the absorption spectra were recorded using Shimadzu-UV 3101 PC UV-VIS-NIR UV-vis spectrophotometer in the range of $200-800 \mathrm{~nm}$. The baseline correction was done using analytical grade $\mathrm{BaSO}_{4}$. FTIR spectra were obtained using NICOLLET IMPACT 400 D FTIR spectrometer. Surface morphology was analysed by SEM analysis using JSM840 microscope operating at $25 \mathrm{kV}$ on specimen upon which thin layer of gold has been evaporated. The X-ray photoelectron spectroscopy (XPS) measurements were carried out using AXIS ULTRA from AXIS 165, integrated with Kratos patented Magnetic immersion lens along with the charge neutralization system and spherical mirror analyzer. The XPS experiments were calibrated accordingto the binding energy of C $1 \mathrm{~s}(284.6 \mathrm{eV})$. The specific surface area and pore volume of the powders were measured by Nova Quanta Chrome Corporation single point BET Digisorb 2006 instrument system in which $\mathrm{N}_{2}$ gas was adsorbed at $77 \mathrm{~K}$.

\subsection{Photochemical reactor and reaction conditions}

Experiments were carried out at room temperature using a circular glass reactor whose surface area is $176.6 \mathrm{~cm}^{2} .125 \mathrm{~W}$ medium pressure mercury vapor lamp is used as the UV light source. The photon flux of the light source was found to be $6.95 \mathrm{~mW} / \mathrm{cm}^{2}$ as determined by ferrioxalate actinometry whose emission wavelength was in the range of $350-400 \mathrm{~nm}$ with the $\lambda$ max around $370 \mathrm{~nm}$. The irradiation was carried out by focusing the light directly into the reaction mixture in the open air condition at a distance of $29 \mathrm{~cm}$. The reaction mixture was continuously stirred.

The aqueous reaction test samples were withdrawn from the reaction mixture at definite time intervals during the reaction process and were centrifuged/filtered through $0.45 \mathrm{~mm}$ Millipore filter paper to separate the catalyst particles. $0.5 \mathrm{ml}$ of phosphate buffer solution (sodium dihydogenphosphate and disodium hydrogenphosphate $\mathrm{pH}=7.2$ ) was added to the reaction mixture filtrate to quench the photo-Fenton reaction. The filtrates were analysed by double beam UV-vis spectroscopic technique (P G instruments Model T80). A typical experiment involves dispersion of $20 \mathrm{mg}$ of $\mathrm{Fe}^{0}$ catalyst in $250 \mathrm{ml} \mathrm{MV}$ dye solution ( $20 \mathrm{ppm}$ ) under the specified $\mathrm{pH}$ condition. The experiments were repeated three times under identical conditions to get the concordant values.

\section{Results and discussion}

\subsection{Characterization of the catalyst}

The X-ray powder diffraction patterns of $\mathrm{Fe}^{0}$ (Fig. 1 ) show peaks at $2 \theta$ values of $44.5^{\circ}(101)$ and $64.97^{\circ}(200)$. The numbers in the 
parenthesis represents $h k l$ values. This pattern matches well with the standard phase of body centred cubic (BCC) structure of $\mathrm{Fe}^{0}$ (JCPDS Standard 87-722) [40]. The average crystallite size of the $\mathrm{Fe}^{0}$ catalyst is calculated by using Scherrer's equation:

$\mathrm{D}=\frac{\mathrm{k} \lambda}{\beta \cos \theta}$

Where $\lambda$ is wavelength of $\mathrm{Cu} K \alpha$ source used, $\beta$ is full width at half maximum (FWHM) of high intense diffraction angle, $\mathrm{k}$ is a shape factor (0.94) and $\theta$ is angle of diffraction. The calculated crystallite size of $\mathrm{Fe}^{0}$ from Scherrer's equation was found to be $17.22 \mathrm{~nm}$. FTIR spectra of metallic $\mathrm{Fe}^{0}$ sample recorded in the frequency range of $400-4000 \mathrm{~cm}^{-1}$ is represented in Fig. 2 . The first peak at $3437 \mathrm{~cm}^{-1}$ corresponds to $\mathrm{OH}$ stretching vibration and second peak at $1643 \mathrm{~cm}^{-1}$ corresponds to $\mathrm{OH}$ bending vibration of surface adsorbed moisture from atmosphere. This probably indicates the formation of a thin layer of ferrioxyhydroxide ( $\mathrm{Fe}-\mathrm{OOH})$ on the surface of $\mathrm{Fe}^{0}$ nanoparticle [41]. The absorption spectrum of $\mathrm{Fe}^{0}$ particles (Fig. 3) shows a broad intense absorption band in the visible region around $400-600 \mathrm{~nm}$, which could probably be assigned to spin allowed $\mathrm{d}-\mathrm{d}$ transitions due to the formation of ferrioxyhydroxide $(\mathrm{FeOOH})$ layer on the surface of $\mathrm{Fe}^{0}$ nanoparticles by the adsorption of moisture. Fig. 4 shows the SEM image of $\mathrm{Fe}^{0}$ particles with average particle size of $40-50 \mu \mathrm{m}$ and the micrograph also indicates the absence of agglomeration.

XPS technique is a highly surface selective process used to explore the surface composition and local chemical environments.The XPS spectra of zero valent metallic iron (Fig. 5) shows Fe 2 p binding energy peaks at $706.7 \mathrm{eV}$ and $713.9 \mathrm{eV}$, which indicates the presence of iron in metallic and +2 oxidation states respectively. The peak at $713.9 \mathrm{eV}$ corresponding to the +2 oxidation state is probably due to the formation of a thin layer of ferrioxyhydroxide $(\mathrm{Fe}-\mathrm{OOH})$ on the surface of $\mathrm{Fe}^{0}$ nanoparticle. The specific

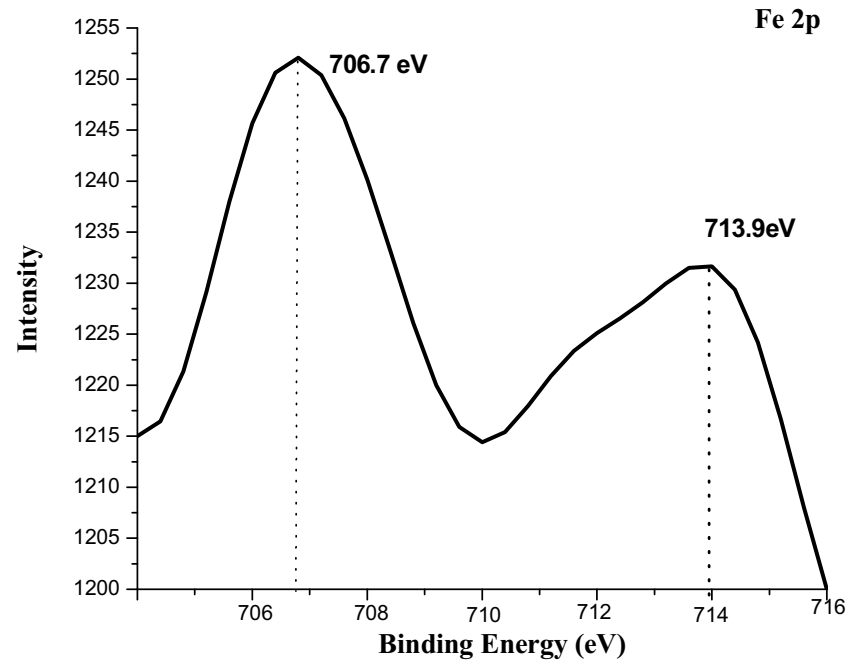

Fig. 5. XPS spectra of $\mathrm{Fe}^{0}$.

surface area of $\mathrm{Fe}^{0}$ sample from BET measurements is found to be $7.0364 \mathrm{~m}^{2} / \mathrm{g}$.

\subsection{Photocatalytic activity}

The application of classical photo-Fenton process is limited by the concentration of ferrous ions in presence of HP to generate the hydroxyl free radicals and more precisely on the ability of the system to regenerate ferrous ions continuously $[42,43]$. The present research focuses on the process of generation of reactive free radicals that differs from classical photo-Fenton process by taking zero

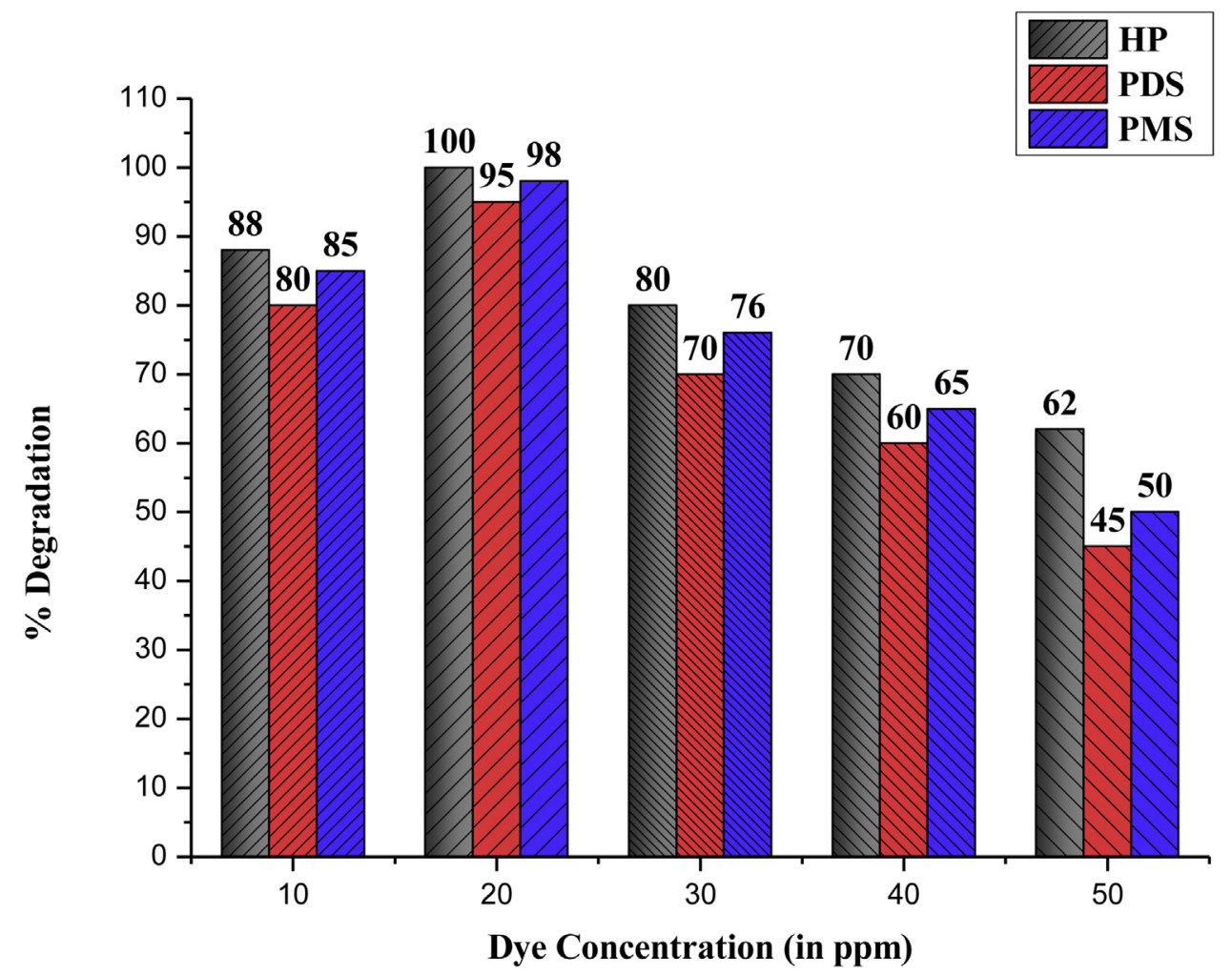

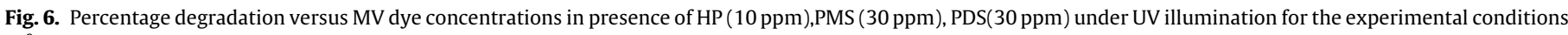
$\mathrm{Fe}^{0}(20 \mathrm{mg}), \mathrm{pH}-3$ for $40 \mathrm{~min}$. 
A

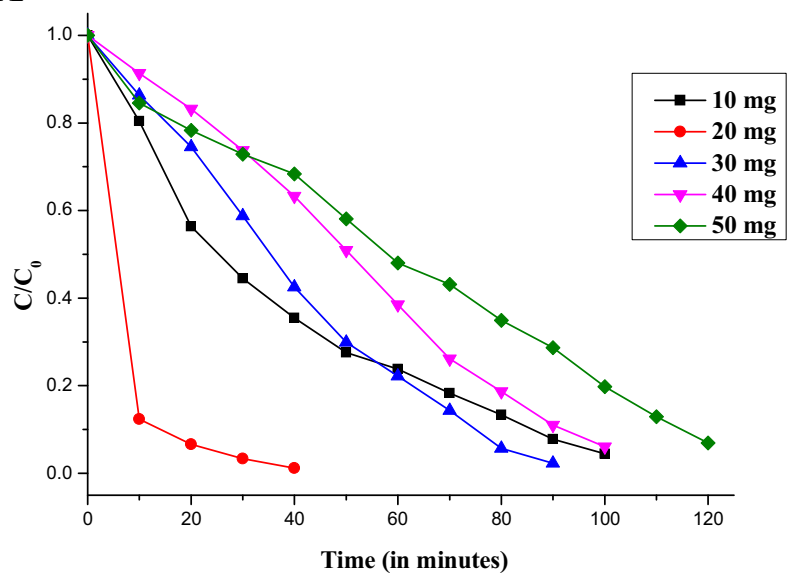

B

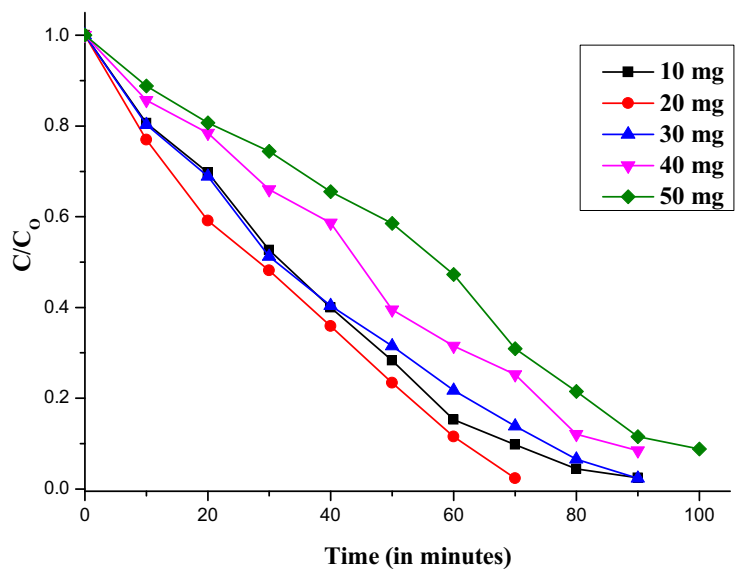

C

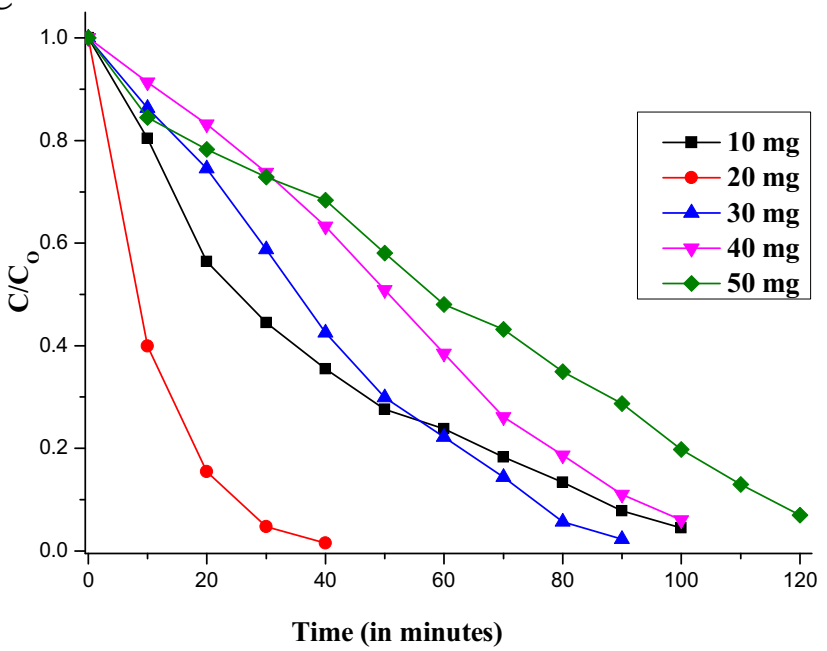

Fig. 7. Percentage degradation versus time plots for the various $\mathrm{Fe}^{0}$ dosages from 10 to $50 \mathrm{mg}$ per $250 \mathrm{ml}$ of $\mathrm{MV}(20 \mathrm{ppm})$ solutions under UV illumination at $\mathrm{pH}-3$, (A) HP (10 ppm), (B) PDS (30 ppm), (C) PMS (30 ppm).

valent metallic iron $\left(\mathrm{Fe}^{0}\right)$ nano particles instead of $\mathrm{Fe}^{2+}$ ions as the iron source along with different oxidants like HP/PDS/PMS and the process is referred to as advanced photo-Fenton process (APFP). Metallic $\mathrm{Fe}^{0}$ surface generates $\mathrm{Fe}^{2+}$ ions in the acidic medium by losing two electrons as shown in Eq. (6). These two liberated electrons are taken up by the $\mathrm{H}_{2} \mathrm{O}_{2}$ molecule, which is an electron acceptor leading to the formation of two hydroxide ions as shown in Eq. (7) and gives rise to highly potent Fenton type reactions. The gener- ated $\mathrm{Fe}^{2+}$ ions are further oxidized to $\mathrm{Fe}^{3+}$ state in the presence of oxidizing agents as shown in Eq. (1). The back reduction reaction of $\mathrm{Fe}^{3+}$ ion to $\mathrm{Fe}^{2+}$ state is faster at the $\mathrm{Fe}^{0}$ surface in APFP compared to the homogeneous Fenton process (Eq. (2)). This faster back reduction reaction gives an added advantage in the APFP and makes it a potential technique for the abatement of hazardous pollutants [23].

$\mathrm{Fe}^{0} \stackrel{\mathrm{H}^{+}}{\longrightarrow} \mathrm{Fe}^{2+}+2 \mathrm{e}^{-}$

$\mathrm{H}_{2} \mathrm{O}_{2}+2 \mathrm{e}^{-} \longrightarrow 2 \mathrm{OH}^{-}$

\subsection{Effect of initial dye concentration}

In the photo Fenton process, change in the initial dye concentration influences the rate of degradation process significantly. Therefore experiments were performed to find the optimum dye concentration for efficient degradation. Initial dye concentrations were varied from 10 to $50 \mathrm{ppm}$ by maintaining the optimum reaction parameters. The optimum dye concentration was found to be $20 \mathrm{ppm}$ as shown in Fig. 6. The degradation efficiency decreases for higher initial dye concentration ( $50 \mathrm{ppm})$. This can be accounted to the fact that, as the dye concentration is increased, the number of hydroxyl radicals are not increased proportionally. Further higher dye concentration leads to a situation where penetration of UV light into the depth of the solution is hindered thereby decreasing the rate of generation of hydroxyl radicals [23]. Further at high dye concentrations, all the active centres on the iron surface will be occupied by the dye molecules which prevents the occupation of oxidant molecules. At high dye concentrations, the dye molecules are capable of reducing the catalyst surface itself. This corrosion process further decreases the concentration of active free radicals which are most essential for sustaining cyclic photo-Fenton process $[44,12]$.

\subsection{Effect of $\mathrm{Fe}^{0}$ dosage}

Concentration of the reactive catalyst $\left(\mathrm{Fe}^{0}\right)$ is a very important parameter in the photo-Fenton process as it influences the extent of generation of highly reactive free radicals. Logically by increasing the $\mathrm{Fe}^{0}$ dosage, higher reaction rates are expected. However, it was noticed that degradation efficiency was high only for low $\mathrm{Fe}^{0}$ concentration $(20 \mathrm{mg})$ and it also leads to complete mineralization of MV. Degradation efficiency was similar for all the three oxidants when used individually (Fig. 7). On further increase of $\mathrm{Fe}^{0}$ dosage (above $20 \mathrm{mg}$ ) degradation rate decreases drastically. The deleterious effect observed for high amounts of $\mathrm{Fe}^{0}$ catalyst can be attributed to the formation of turbidity in the aqueous reaction suspension. This turbidity would cause a relevant fraction of the incident radiation to be lost via scattering thereby decreasing the rate of absorption. Photo-Fenton process is hindered by the turbidity to a maximum extent, however minimal Fenton process can still sustain to some extent in such reaction conditions. Similar results are also reported in the literature [45]. The excess iron in the solution precipitates as iron hydroxide and it gets deposited on the $\mathrm{Fe}^{0}$ surface leading to the decrease in the degradation rate. This clearly indicates that higher dosage of $\mathrm{Fe}^{0}$ catalyst is undesirable for efficient photodegradation.

\subsection{Effect of $\mathrm{pH}$ on the degradation rate}

The $\mathrm{pH}$ of the aqueous reaction medium is a crucial operating parameter in photo Fenton reactions. $\mathrm{pH}$ directly affects the catalytic performance of $\mathrm{Fe}^{0}$ and it also effects the extent of iron leaching. There is a general agreement in the literature about the optimal pH being close to 3 and it is the highly reported typical value for the homogeneous photo-Fenton process [46]. However, in the 


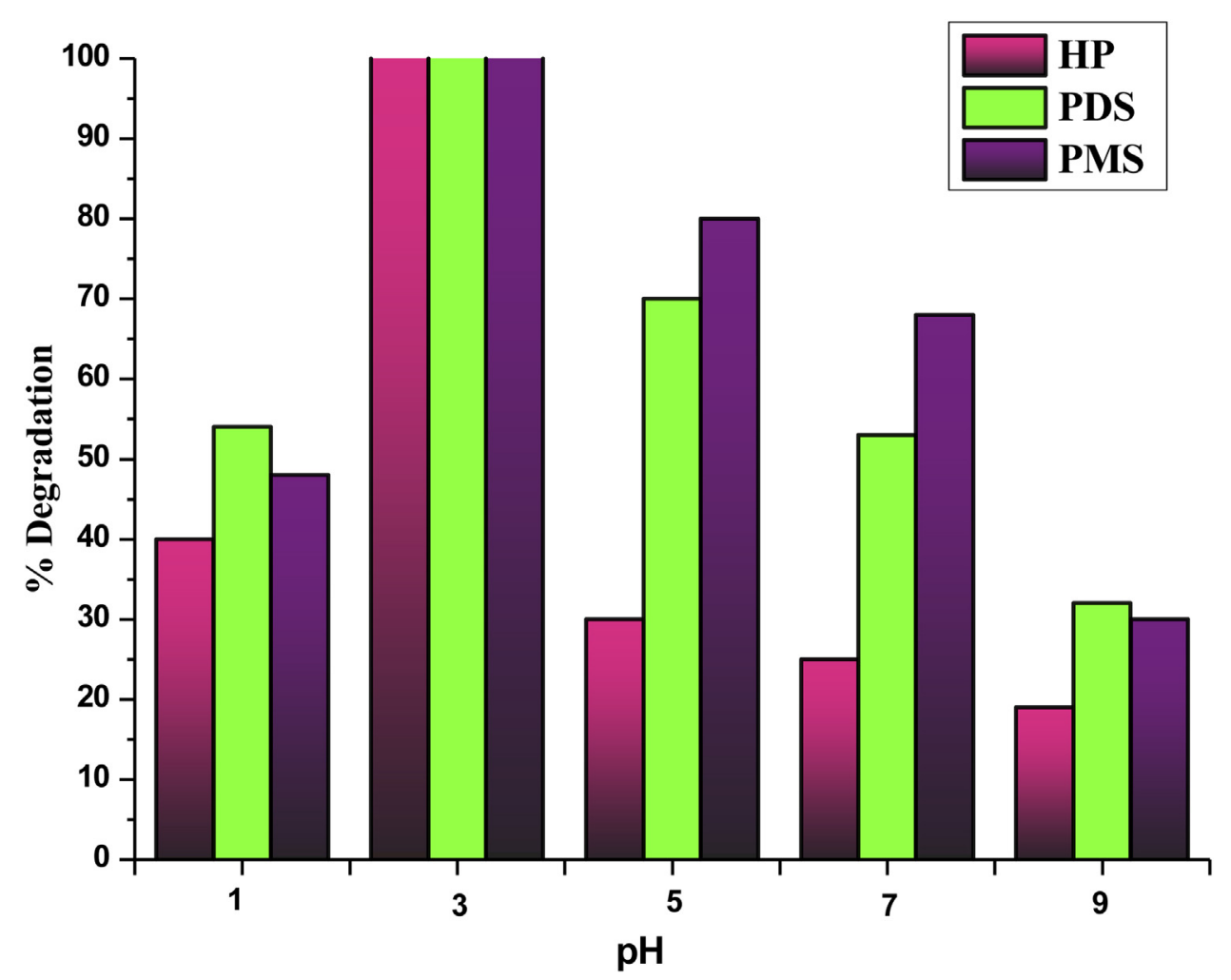

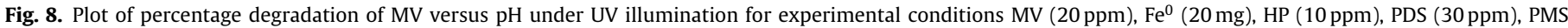
(30 ppm) for $40 \mathrm{~min}$.

present case the photo-Fenton reaction systems were examined at five different $\mathrm{pH}$ values $(1.0,3.0,5.07 .0$ and 9.0$)$ by maintaining the experimental conditions of optimized $\mathrm{Fe}^{0}$ dosage and oxidant concentration. Higher efficiency was found at $\mathrm{pH} 3.0$ for all the three oxidants (Fig. 8). It was probably due to the maximum activity of iron at acidic $\mathrm{pH}$ conditions.

The extent of iron activation by $\mathrm{H}_{2} \mathrm{O}_{2}$ is highly $\mathrm{pH}$ dependent and the most ideal $\mathrm{pH}$ for this reaction was found to be in the range of 3.0-4.0. The prominent decrease in the degradation rate at lower $\mathrm{pH}$ conditions $(\sim 1)$ is due to the presence of excess $\mathrm{H}^{+}$ions in the solution which acts as hydroxyl radical scavengers according to Eq. (8) [47].

$\mathrm{H}^{+}+\mathrm{OH}^{\bullet}+\mathrm{e}^{-} \longrightarrow \mathrm{H}_{2} \mathrm{O}$

At $\mathrm{pH} 3$, the concentration of $\mathrm{Fe}^{3+}$ ions and $[\mathrm{Fe}(\mathrm{OH})]^{2+}$ ions are equal in proportion to one another which is the most favourable condition in a photo-Fenton reaction. These ions are dominant photoactive species and hence the degradation reaction rate is maximum at this $\mathrm{pH}$ condition [48]. Further increase in the pH leads to the decrease in degradation efficiency for the following reasons: (i) Iron precipitates as oxyhydroxides, (ii) The ratio of concentration of $\mathrm{Fe}^{3+}$ ions to $[\mathrm{Fe}(\mathrm{OH})]^{2+}$ ions gets disproportionate, which prevents the efficient generation of hydroxyl radicals (iii) The presence of deposited oxyhydroxide on $\mathrm{Fe}^{0}$ surface blocks the electron transfer process between the catalyst and the oxidant, (iv) The oxidation potential of hydroxyl radical is also influenced by the $\mathrm{pH}$ and it is expected to decrease with the increase in $\mathrm{pH},(\mathrm{v})$ Coagulation of excess $\mathrm{Fe}^{3+}$ ions takes place at higher $\mathrm{pH}$ conditions and (vi) This coagulated $\mathrm{Fe}^{3+}$ ions inhibit the formation/regeneration of $\mathrm{Fe}^{2+}$ ions which are required for sustaining the cyclic photo-Fenton reaction [39].
$\mathrm{Fe}^{0} / \mathrm{HP} / \mathrm{UV}$ process was highly efficient compared to $\mathrm{Fe}^{0} / \mathrm{PDS} / \mathrm{UV}$ and $\mathrm{Fe}^{0} / \mathrm{PMS} / \mathrm{UV}$ systems. $90 \%$ of the degradation is completed within $10 \mathrm{~min}$ in the case of HP and 20 min in the case of PMS. But such efficiency was not observed in the case of PDS where complete degradation takes place around $70 \mathrm{~min}$.

The $\mathrm{Fe}^{0} / \mathrm{PMS} / \mathrm{UV}$ and $\mathrm{Fe}^{0} / \mathrm{PDS} / \mathrm{UV}$ photo-Fenton reactions at $\mathrm{pH}$ 5 are more remarkable as compared to $\mathrm{Fe}^{0} / \mathrm{HP} / \mathrm{UV}$ system. Further interesting results were observed for the reactions of the type PMS/UV and PDS/UV systems which show almost similar efficiency as $\mathrm{Fe}^{0} / \mathrm{PMS} / \mathrm{UV}$ and $\mathrm{Fe}^{0} / \mathrm{PDS} / \mathrm{UV}$ process. More precisely the role of $\mathrm{Fe}^{0}$ is insignificant at this $\mathrm{pH}$, since most of the $\mathrm{Fe}^{0}$ surface is covered by the hydroxide and oxyhydroxides. PMS in PMS/UV system is activated to form $\mathrm{PDS}$ at $\mathrm{pH} 5$ under UV irradiation and this reaction process can be compared to PDS/UV system. On the other hand PDS under UV illumination generates $\mathrm{SO}_{4}{ }^{-}$. free radicals which are more prominent in the degradation reactions (as shown in Eqs. (9)-(12)).

PMS can only exist as highly reactive monoanion form $\left(\mathrm{HSO}_{5}{ }^{-}\right)$ in the acidic $\mathrm{pH}$ range from 3 to 7 . However at higher $\mathrm{pH}$ values (above 7) PMS exists as less reactive dianion form $\left(\mathrm{SO}_{5}{ }^{2-}\right)$. The efficient generation of $\mathrm{SO}_{4}{ }^{-} \bullet$ takes place only from monoanion form $\left(\mathrm{HSO}_{5}{ }^{-}\right)$and its generation is almost insignificant from dianion form $\left(\mathrm{SO}_{5}{ }^{2-}\right)$. Decrease in efficiency at higher $\mathrm{pH}$ values $(\geq \mathrm{pH} 7)$ was attributed to dominant process of self-decomposition of PMS $[49,39]$.

PMS $\stackrel{\mathrm{h} v}{\longrightarrow}$ PDS (at $\mathrm{pH} \mathrm{5)}$

$\mathrm{SO}_{5}{ }^{-\bullet}+\mathrm{SO}_{5}{ }^{-\circ} \longrightarrow \mathrm{SO}_{4}^{-\circ}+\mathrm{SO}_{4}^{-\circ}+\mathrm{O}_{2}$

$\mathrm{SO}_{5}{ }^{-\bullet}+\mathrm{SO}_{5}^{-\bullet} \longrightarrow$ PDS+ $\mathrm{O}_{2}$

$\mathrm{PDS} \stackrel{\mathrm{h} v}{\longrightarrow} \mathrm{OH}^{\circ}+\mathrm{SO}_{4}{ }^{-\circ}$ 
A

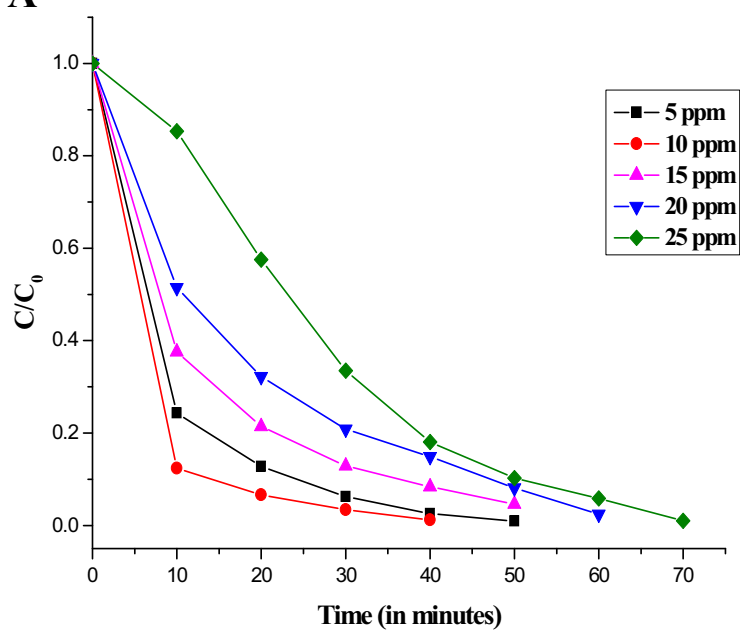

B

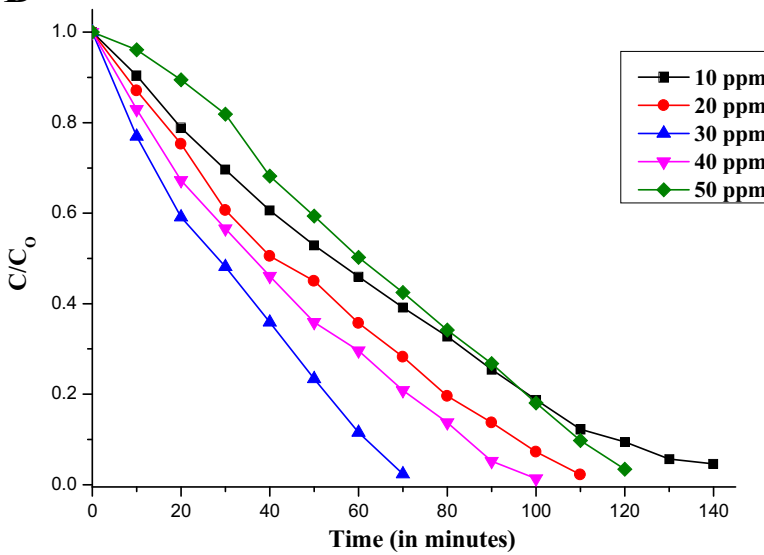

C

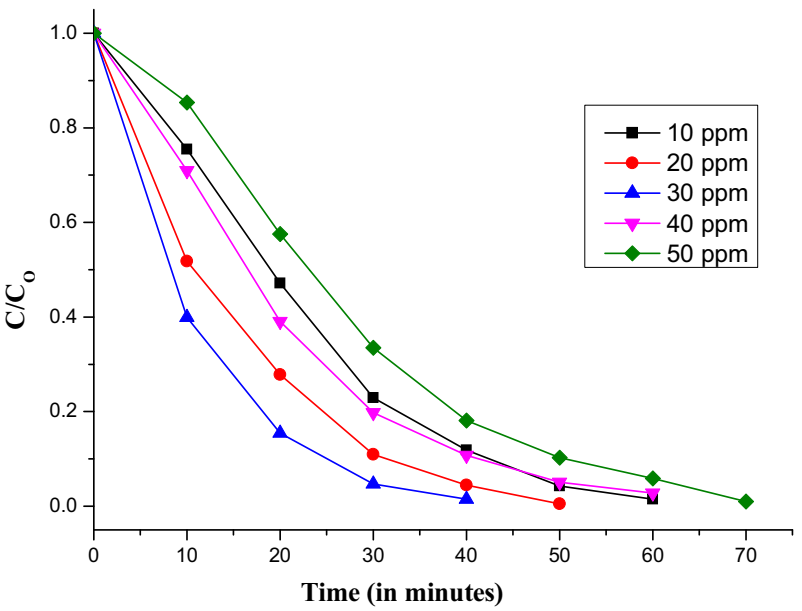

Fig. 9. Percentage degradation versus time plots under optimized experimental conditions of MV $(20 \mathrm{ppm}), \mathrm{Fe}^{0}(20 \mathrm{mg})$ at $\mathrm{pH}-3$. Effect of various concentration of: (A) HP, (B) PDS and (C) PMS

\subsection{Effect of oxidants}

In a photo-Fenton system, the concentration of the oxidant (HP, PDS and PMS) is a key factor that can significantly influence the rate of degradation (Fig. 9). The individual influence of each oxidant was studied by maintaining optimum $\mathrm{Fe}^{0}$ dosage at $\mathrm{pH} 3$.
Both $\mathrm{HOOH}$ (hydrogen peroxide) and $\mathrm{S}_{2} \mathrm{O}_{8}{ }^{2-}$ (peroxy disulfate) are symmetrical peroxides where as $\mathrm{HSO}^{-}{ }_{5}$ (peroxy monosulfate) is an unsymmetrical peroxide molecule. The UV irradiation activates the oxidants through homolytic cleavage of the peroxide bond which results in the formation of hydroxyl and sulfate radicals depending on the chemical nature of the oxidant as well as the reaction conditions. Under light induced reaction processes, HP generates hydroxyl free radicals, PDS generates sulfate radicals and PMS generates both sulfate and hydroxyl radicals as shown in Eqs. (13)-(15). Sulfate free radicals provide similar degradation reaction pathway as that of hydroxyl radical generated in the classical Fenton's chemistry [50].

$$
\begin{aligned}
& \mathrm{H}-\mathrm{O}-\mathrm{O}-\mathrm{H} \stackrel{\mathrm{h} v}{\longrightarrow} \mathrm{OH}^{\bullet}+\mathrm{OH}^{\bullet} \\
& -\mathrm{SO}_{3}-\mathrm{O}-\mathrm{O}-\mathrm{SO}_{3}^{-} \stackrel{\mathrm{h} v}{\longrightarrow} \mathrm{SO}_{4}^{-\circ}+\mathrm{SO}_{4}^{-\bullet} \\
& \mathrm{H}-\mathrm{O}-\mathrm{O}-\mathrm{SO}_{3}^{-} \stackrel{\mathrm{h} v}{\longrightarrow} \mathrm{OH}^{\bullet}+\mathrm{SO}_{4}^{-}
\end{aligned}
$$

However, $\mathrm{Fe}^{0}$ catalyst particles activate the oxidants (HP, PDS and PMS) by the cleavage of peroxo bond under UV light to produce ferrous ions which later generates various reactive free radicals through electron transfer mechanism and gets oxidized to $\mathrm{Fe}^{3+}$ ions. The regeneration of $\mathrm{Fe}^{2+}$ ions from $\mathrm{Fe}^{3+}$ ions is a continuous cyclic process which takes place until complete consumption of oxidant (as shown in Eqs. (1)-(2) and (16)-(24)) [36].

$$
\begin{aligned}
& \mathrm{Fe}^{0}+\mathrm{H}_{2} \mathrm{O}_{2} \rightarrow \mathrm{Fe}^{2+}+2 \mathrm{OH}^{-} \\
& \mathrm{Fe}^{3+}+\cdot \mathrm{O}_{2} \mathrm{H}+\mathrm{H}^{+} \rightarrow \mathrm{Fe}^{2+}+\mathrm{H}_{2} \mathrm{O}_{2} \\
& \mathrm{Fe}^{0}+\mathrm{S}_{2} \mathrm{O}_{8}^{2-} \rightarrow \mathrm{Fe}^{2+}+2 \mathrm{SO}_{4}^{2-} \\
& \mathrm{Fe}^{2+}+\mathrm{S}_{2} \mathrm{O}_{8}^{2-} \rightarrow \mathrm{Fe}^{3+}+\mathrm{SO}_{4}^{2-}+\mathrm{SO}_{4}^{-} \cdot \\
& \mathrm{Fe}^{3+}+\mathrm{S}_{2} \mathrm{O}_{8}^{2-} \rightarrow \mathrm{Fe}^{2+}+2 \mathrm{SO}_{4}^{2-} \\
& \mathrm{Fe}^{0}+\mathrm{HSO}_{5}{ }^{2-} \rightarrow \mathrm{Fe}^{2+}+\mathrm{SO}_{4}^{2-}+\mathrm{OH}^{-} \\
& \mathrm{Fe}^{2+}+\mathrm{HSO}_{5}{ }^{-} \rightarrow \mathrm{Fe}^{3+}+\mathrm{SO}_{4}^{-} \cdot+\mathrm{OH}^{-} \\
& \mathrm{Fe}^{3+}+\mathrm{HSO}_{5}{ }^{-} \rightarrow \mathrm{Fe}^{2+}+\mathrm{SO}_{4}^{2-}+\mathrm{OH}^{-} \\
& \mathrm{SO}_{4}{ }^{-} \cdot \mathrm{H}_{2} \mathrm{O}_{2} \rightarrow \mathrm{SO}_{4}{ }^{2-}+\mathrm{OH}^{\bullet}+\mathrm{H}^{+}
\end{aligned}
$$

The Fig. $9 A-C$ shows the plot of $C / C_{0}$ versus time for the photo Fenton process involving three different oxidants at various concentrations as mentioned in the figure. In the case of HP (Fig. 9A) with increase in concentration from $5 \mathrm{ppm}$ to $25 \mathrm{ppm}$ the degradation efficiency is expected to increase. This is because $\mathrm{H}_{2} \mathrm{O}_{2}$ concentration is directly related to the number of hydroxyl radicals generated which actively participate in the photodegradation reaction. But at high HP dosage, recombination reaction of hydroxyl radicals dominate (Eqs. (25)-(27)) and hence the rate of degradation decreases marginally.

$$
\begin{aligned}
& \mathrm{H}_{2} \mathrm{O}_{2}+\mathrm{OH}^{\bullet} \rightarrow \mathrm{HO}_{2}^{\circ}+\mathrm{H}_{2} \mathrm{O} \\
& \mathrm{HO}_{2}^{\circ}+\mathrm{OH}^{\bullet} \rightarrow \mathrm{H}_{2} \mathrm{O}+\mathrm{O}_{2} \\
& \mathrm{OH}^{\bullet}+\mathrm{OH}^{\bullet} \rightarrow \mathrm{H}_{2} \mathrm{O}_{2}
\end{aligned}
$$

Similar results were obtained in the case of PMS and PDS. Beyond the optimum concentration, the degradation rate remains almost constant. The excess free radicals generated may undergo recombination or may get involved in the undesired side reactions. The optimized PMS and PDS concentrations were found to be $30 \mathrm{ppm}$ respectively. The results from Fig. 10 reveal that the efficiency of $\mathrm{Fe}^{0} / \mathrm{HP} / \mathrm{UV}$ is almost similar to $\mathrm{Fe}^{0} / \mathrm{PMS} / \mathrm{UV}$ system. This suggests that PMS can be more easily activated by ferrous ion under UV irradiation at $\mathrm{pH} 3$. 


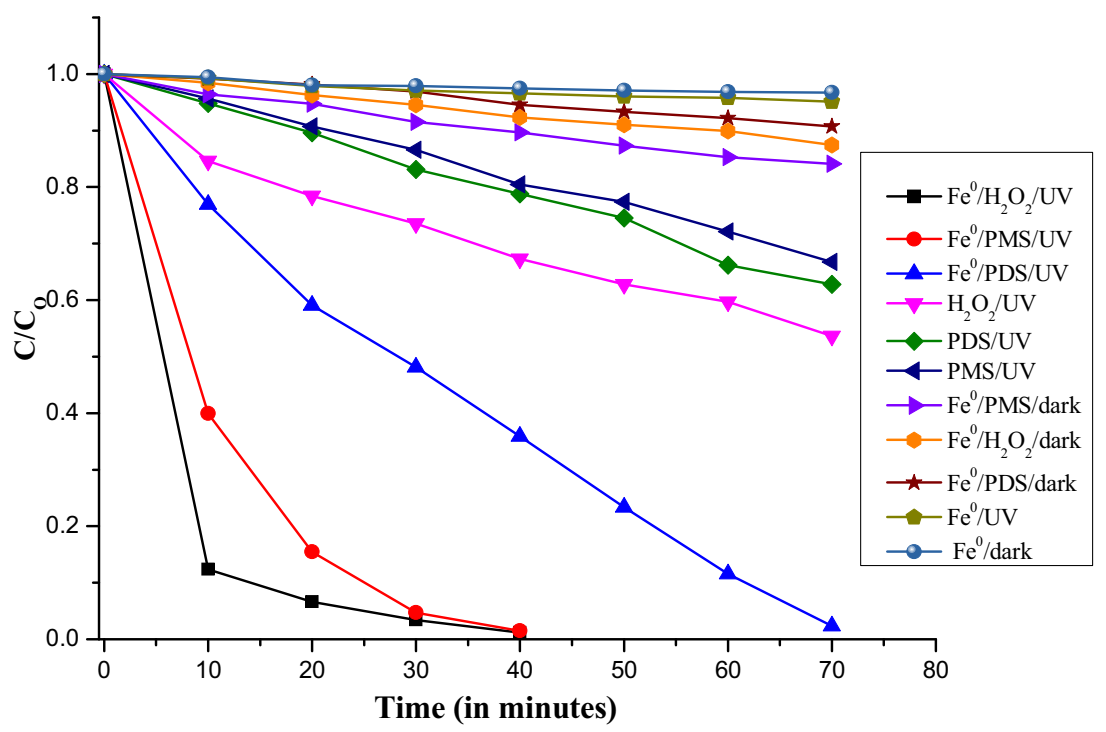

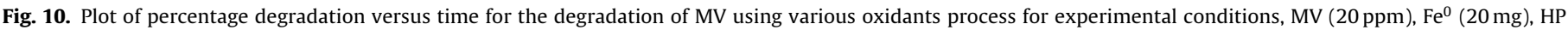
(10 ppm), PDS (30 ppm), PMS (30 ppm), pH-3.

\subsection{Comparative study of HP, PDS and PMS oxidant activity}

HP, PDS and PMS have similar structures and they all have $\mathrm{O}-\mathrm{O}$ bond. It can be analysed that if one hydrogen atom in HP $(\mathrm{H}-\mathrm{O}-\mathrm{O}-\mathrm{H})$ is replaced by $\mathrm{SO}_{3}$, it results in the formation of PMS $\left(\mathrm{H}-\mathrm{O}-\mathrm{O}-\mathrm{SO}_{3}\right)$ and if two hydrogen atoms are replaced by $\mathrm{SO}_{3}$ leads to the formation of PDS $\left(\mathrm{SO}_{3}-\mathrm{O}-\mathrm{O}-\mathrm{SO}_{3}\right)$. This increases the $\mathrm{O}-\mathrm{O}$ bond length accompanied with decrease in the bond energy. The lengths of $\mathrm{O}-\mathrm{O}$ bond in HP, PMS and PDS are found to be $1.453,1.460$ and $1.497 \AA$ respectively [51,52]. The bond energy of $\mathrm{O}-\mathrm{O}$ bond in PDS is estimated to be $140 \mathrm{~kJ} / \mathrm{mol}$ and in HP it is $213.3 \mathrm{~kJ} / \mathrm{mol}$ whereas no authentic data about bond energy of $\mathrm{O}-\mathrm{O}$ is available for PMS. [53,54]. However, PMS posses unsymmetrical structure, the $\mathrm{SO}_{3}$ group can attract electron and this end of $\mathrm{O}-\mathrm{O}$ bond is negatively charged and the $\mathrm{H}$-side is positively charged $\left({ }^{-} \mathrm{O}_{3} \mathrm{~S}-\mathrm{O}-\mathrm{O}-\mathrm{H}^{+}\right)$. The standard redox potentials $\mathrm{E}^{0}$ of these oxidants vary in the following way: PDS (2.01) $>$ PMS (1.82) $>\mathrm{HP}$ (1.776). From the bond length and bond energy values, PDS is inferred to be a better oxidant. But the experimental observations show PMS to be a better oxidant. This higher activity of PMS can be accounted for its unsymmetrical structure with dipolar charge distribution and also to the lower unoccupied molecular orbital (LUMO) energy levels. As early as 1956, Ball and Edward have reported the superiority of PMS for its high reactivity around neutral pH for decomposing/oxidizing capability of both organic and inorganic compounds [55]. In addition to the flexibility of its use over a wide $\mathrm{pH}$ range, $\mathrm{SO}_{4}{ }^{-\bullet}$ posses higher redox potential of $2.5-3.1 \mathrm{~V}$ at neutral $\mathrm{pH}$ compared to the redox potentials of hydroxyl free radicals (1.8-2.7 V) [46]. Further in a photochemicaloxidation reaction sulfate free radicals are also non-selective like hydroxyl free radicals. Antoniou et al. reported that the oxidizing property of an oxidant depends on the ability to accommodate an electron by the LUMO energy levels [24]. The molecule with low lying lower LUMO energy can accommodate electrons more readily and higher will be its oxidizing property. The LUMO energies of these three oxidants show the following decreasing order: PDS $>\mathrm{H}_{2} \mathrm{O}_{2}>$ PMS. Hence PMS with higher oxidation potential and with lower LUMO energy can easily accommodate and accept electrons compared to the other two oxidants and it acts as a better oxidant in photo-Fenton reactions [29].

\subsection{Recycling efficiency of iron powder}

The recycling efficiency of $\mathrm{Fe}^{0}$ catalyst was tested under the optimized experimental conditions. After the completion of each experiment, $\mathrm{Fe}^{0}$ powder was collected and washed with double distilled water for 2-3 times. A fresh dye solution along with the oxidant is taken in the photo-reactor with the recycled $\mathrm{Fe}^{0}$ catalyst. Experiments were carried out for $2 \mathrm{~h}$ duration with each of the three oxidants. In case of HP complete mineralization of MV was achieved for the first two repeated cycles. The efficiency was reduced to 80 percent from third to fifth run and it further decreased to 50 percent for sixth to tenth run. Beyond this repetitive cycle the catalyst surface showed resistance for further degradation. In the case of PDS and PMS, the efficiency of the $\mathrm{Fe}^{0}$ powder is well retained for the first two experimental runs, 70 percent for third to fifth and the efficiency decreases to 20 percent beyond sixth cycle. Hence, it can be concluded that HP acts as a better oxidant compared to PMS and PDS in retaining the catalytic efficiency of $\mathrm{Fe}^{0}$ surface in the recycling process. $\mathrm{Fe}^{0}$ powder undergoes excess dissolution as $\mathrm{Fe}^{2+}$ ions in photocatalytic-oxidation reactions with sulfate based PMS and PDS oxidants and hence the recycling efficiency decreases slightly.

\section{Conclusion}

This research study was focused on the highly efficient advanced photo-Fenton process involving $\mathrm{Fe}^{0}$ surface in the presence of hydroxyl and sulfate based oxidants of the type HP/PMS/PDS. The influence of various reaction parameters like iron dosage, initial dye and oxidant concentration is investigated in detail and optimum conditions are reported. It was observed that higher dosage of iron decreases the degradation rate by precipitation of $\mathrm{Fe}$ as its hydroxides. At higher $\mathrm{pH}$ values precipitation of iron as oxyhydroxides takes place and the ratio of concentrations of $\mathrm{Fe}^{3+}$ ions to $[\mathrm{Fe}(\mathrm{OH})]^{2+}$ ions gets disproportionate, decreasing the concentration of hydroxyl free radicals. At pH 5, PMS/UV and PDS/UV systems show similar efficiencies as $\mathrm{Fe}^{0} / \mathrm{PMS} / \mathrm{UV}$ and $\mathrm{Fe}^{0} / \mathrm{PDS} / \mathrm{UV}$ process since the $\mathrm{Fe}^{0}$ surface is almost covered by oxyhydroxides. The generation of $\mathrm{SO}_{4}{ }^{-\cdot}$ radicals is most efficient only from monoanion form $\left(\mathrm{HSO}_{5}{ }^{-}\right)$and it is almost insignificant from dianion form $\left(\mathrm{SO}_{5}{ }^{2-}\right)$ at pH 7. PMS is proved to be a better oxidant compared to HP and PDS 
especially at higher $\mathrm{pH}$ values. The higher activity of PMS can be attributed to its unsymmetrical structure with dipolar charge distribution and also to the low lying LUMO energy levels which are most essential for accepting the electrons. Iron powder retained its recycling efficiency for the first four runs in case of all the oxidants. However for the subsequent runs, the efficiency was retained in the case of HP compared to PMS and PDS.

\section{Acknowledgements}

Authors acknowledge the financial assistance from University Grants Commission (UGC) and Department of Science and Technology (DST), Government of India.

\section{References}

[1] Z. Ai, H. Xiao, T. Mei, J. Liu, L. Zhang, K. Deng, J. Qiu, Photothermal synthesis of $\mathrm{Cu}_{\mathrm{x}} \mathrm{O}$ nanoparticles on carbon nanotubes for photosensitized degradation, J. Phys. Chem. C 112 (2008) 11929-11935.

[2] F. Mendez-Arriaga, S. Esplugas, J. Gimenez, Degradation of the emerging contaminant ibuprofen in water by photo-fenton, Water Res. 44 (2010) 589-595.

[3] R. Andreozzi, V. Caprio, A. Insola, R. Marotta, Advanced oxidation processes (AOP) for water purification and recovery, Catal. Today 53 (1999) 51-59.

[4] M. Pera-Titus, V. Garcia-Molina, M.A. Banos, J. Gimenez, S. Espulgas, Degradation of chlorophenols by means of advanced oxidation processes: a general review, Appl. Catal.B: Environ. 47 (2004) 219-256.

[5] E.G. Garrido-Ramirez, B.K.G. Theng, M.L. Mora, Clays and oxide minerals as catalysts and nanocatalysts in fenton-like reactions - a review, Appl. Clay Sci. 47 (2010) 182-192.

[6] J. Herney-Ramirez, L.M. Madeira, in: A. Gil, S.A. Korili, R. Trujillano, M.A. Vicente (Eds.), Pillared Clays and Related Catalysts, Springer, 2010

[7] X. Guan, Y. Sun, H. Qin, J. Li, Irene M.C. Lo, Di He, H. Dong, The limitations of applying zero-valent iron technology in contaminants sequestration and the corresponding countermeasures: the development in zero-valent iron technology in the last two decades (1994-2014), Water Res. 75 (2015) 224-248.

[8] A. Babuponnusami, K. Muthukumar, A review on Fenton and improvements to the Fenton process for wastewater treatment, J. Environ. Chem. Eng. 2 (2014) 557-572

[9] A.D. Bokare, W. Choi, Review of iron-free Fenton-like systems for activating $\mathrm{H}_{2} \mathrm{O}_{2}$ in advanced oxidation processes, J. Hazard. Mater. 275 (2014) 121-135.

[10] H.J.H. Fenton, Oxidation of tartaric acid in Presexce of iron J, Chem. Soc. 65 (1894) 899-910.

[11] F. Haber, J. Weiss, The catalytic decomposition of hydrogen peroxide by iron salts, Proc. R. Soc. London Ser. A 147 (1934) 332-351.

[12] J. Herney-Ramirez, M.A. Vicente, L.M. Madeira, Heterogeneous photo-fenton oxidation with pillared clay-based catalysts for wastewater treatment: a review, Appl Catal. B: Environ. 98 (2010) 10-26.

[13] O.S.N. Sum, J. Feng, X. Hu, P.L. Yue, Photo-assisted fenton mineralization of an azo-dye acid black 1 using a modified laponite clay-based Fe nanocomposite as a heterogeneous catalyst, Top. Catal. 33 (2005) 233-242.

[14] T. Maezono, M. Tokumura, M. Sekine, Y. Kawase, Hydroxyl radical concentration profile in photo-fenton oxidation process: generation and consumption of hydroxyl radicals during the discoloration of azo-dye orange II, Chemosphere 82 (2011) 1422-1430.

[15] S.R. Pouran, A.R.A. Aziz, W.M.A.W. Daud, Z. Embong Study on the treatment of simulated coking wastewater by $\mathrm{O}_{3}$ and $\mathrm{O}_{3}$ /fenton processes in a rotating packed bed, Appl. Surf. Sci. 351 (2015) 175-187.

[16] Q. Zhai, L. Zhang, X. Zhao, H. Chen, D. Yin, J. Li, A novel iron-containing polyoxometalate heterogeneous photocatlyst for efficient 4-chlorophenol degradation by H2O2 at neutral pH apllied, Appl. Surf. Sci. 377 (2016) 17-22.

[17] L. Zhang, H. Zeng, Y. Zeng, Z. Zhang, X. Zhao, Heterogeneous Fenton-like degradation of 4-chlorophenol using a novel $\mathrm{Fe}^{\mathrm{III}}$-containing polyoxometalate as the catalyst, J. Mol. Catal. A: Chem. 392 (2014) 202-207.

[18] S. Valizadeh, M.H. Rasoulifard, M.S.S. Dorraji, Modified $\mathrm{Fe}_{3} \mathrm{O}_{4}$ - hydroxyapatite nanocomposites as heterogeneous catalysts in three UV Vis and Fenton like degradation systems, Appl. Surf. Sci. 319 (2014) 358-366.

[19] D. Yin, L. Zhang, X. Zhao, H. Chen, Q. Zhai Chinese, Iron-glutamate-silicotungstate ternary complex as highly active heterogeneous fenton-like catalyst for 4-chlorophenol degradation, J. Catal. 36 (2015) 2203-2210.

[20] T.L. Johnson, M.M. Scherer, P.G. Tratnyek, Kinetics of halogenated organic compound degradation by iron metal, Environ. Sci. Technol. 30 (1996) 2634-2640.

[21] S.F. Cheng, S.C. Wu, The enhanced method for degradation of TCE by zero valent metals, Chemosphere 41 (2000) 1263-1270.

[22] A. Ghauch, Degradation of benomyl, picloram and dicamba in a conical apparatus by zero valent iron powder, Chemosphere 43 (2001) 1109-1117.

[23] L.G. Devi, S.G. Kumar, K.M. Reddy, C. Munikrishnappa, Photo degradation of methyl orange an azo dye by advanced fenton process using zero valent metallic iron: influence of various reaction parameters and its degradation mechanism, J. Hazard. Mater. 164 (2009) 459-467.

[24] L.G. Devi, S.G. Kumar, K.M. Reddy, C. Munikrishnappa, Effect of various inorganic anions on the degradation of congo red a diazo dye, by the photo-assisted fenton process using zero-valent metallic iron as catalyst, Desal, Water Treat. 4 (2009) 294-305.

[25] L.G. Devi, K.S.A. Raju, S.G. Kumar, K.E. Rajashekhar, Photo-degradation of diazo dye bismarck brown by advanced photo-fenton process: influence of inorganic anions and evaluation of recycling efficiency of iron powder, J. Taiwan Inst. Chem. Eng. 42 (2011) 341-349.

[26] L.G. Devi, K.E. Rajashekhar, K.S.A. Raju, S.G. Kumar, Influence of various aromatic derivatives on the advanced photo Fenton degradation of Amaranth dye, Desalination 270 (2011) 31-39.

[27] L.G. Devi, C. Munikrishnappa, B. Nagaraj, K.E. Rajashekhar, Effect of chloride and sulfate ions on the advanced photo Fenton and modified photo Fenton degradation process of Alizarin Red S, J. Mol. Catal. A: Chem. 374-375 (2013) $125-131$.

[28] G.P. Anipsitakis, D.D. Dionysiou, Degradation of organic contaminants in water with sulfate radicals generated by the conjunction of peroxymonosulfate with cobalt, Environ. Sci. Technol. 37 (2003) 4790-4797.

[29] M.G. Antoniou, A.A. de la Cruz, D.D. Dionysiou, Degradation of microcystin-LR using sulfate radicals generated through photolysis, thermolysis and etransfer mechanisms, Appl. Catal. B: Environ. 96 (2010) 290-298.

[30] Y. Deng, C.M. Ezyske, Sulfate radical-advanced oxidation process (SR-AOP) for simultaneous removal of refractory organic contaminants and ammonia in landfill leachate, Water Res. 45 (2011) 6189-6194.

[31] A. Ghauch, A.M. Tuqan, N. Kibbi, Ibuprofen removal by heated persulfate in aqueous solution: a kinetics study, Chem. Eng. J. 197 (2012) 483-492.

[32] Y.R. Wang, W. Chu, Degradation of 2,4,5-trichlorophenoxyacetic acid by a novel electro-Fe(II)/Oxone process using iron sheet as the sacrificial anode, Water Res. 45 (2011) 3883-3889.

[33] C.S. Liu, K. Shih, C.X. Sun, F. Wang, Oxidative degradation of propachlor by ferrous and copper ion activated persulfate, Sci. Total Environ. 416 (2012) 507-512.

[34] X.-R. Xu, X.-Z. Li, Degradation of azo dye Orange G in aqueous solutions by persulfate with ferrous ion, Sep. Purif. Technol. 72 (2010) 105-111.

[35] T.T. Tsai, C.M. Kao, A. Hong, Treatment of tetrachloroethylene-contaminated groundwater by surfactant-enhanced persulfate/BOF slag oxidation?a laboratory feasibility study, J. Hazard Mater. 171 (2009) 571-576.

[36] P. Yang, X. Wang, L. Yang, W. Shan, X. Zhang, R. Shao, R. Niu, Degradation efficiencies of azo dye acid orange 7 by the interaction of heat, UV and anions with common oxidants: persulfate, peroxymonosulfate and hydrogen peroxide, J. Hazard. Mater. 179 (2010) 552-558.

[37] H. Kusic, I. Peternel, S. Ukic, N. Koprivanac, T. Bolanca, S. Papic, A.L. Bozic, Iron activated persulphate based advanced oxidation and mineralization of an azo dye, Chem. Eng. J. 172 (2011) 109-121.

[38] A. Rastogi, S.R. Al-Abed, D.D. Dionysiou, Sulfate radical-based ferrous-peroxymonosulfate oxidative system for PCBs degradation in aqueous and sediment systems, Appl. Catal. B: Environ. 85 (2009) 171-179.

[39] J.A. Khan, X. He, H.M. Khan, N.S. Shah, D.D. Dionysiou, Oxidative degradation of atrazine in aqueous solution by $\mathrm{UV} / \mathrm{H}_{2} \mathrm{O}_{2} / \mathrm{Fe}^{2+}: \mathrm{UV} / / \mathrm{Fe}^{2+}$ and $\mathrm{UV} / / \mathrm{Fe}^{2+}$ processes: a comparative study, Chem. Eng. J. 218 (2013) 376-383.

[40] S.H. Piao, M. Bhaumik, A. Maity, H.J. Choi, Magnetorheological suspensions based on modified carbonyl iron particles with an extremely thin poly(n-butyl acrylate) layer and their enhanced stability properties, J. Mater. Chem. C 3 (2015) 1861-1868.

[41] R. Singh, V. Misra, R.P. Singh, Synthesis, characterization and role of zero-valent iron nanoparticle in removal of hexavalent chromium from chromium-spiked soil, J. Nanopart. Res. 13 (2011) 4063-4073.

[42] L.G. Devi, S.G. Kumar, K.M. Reddy, Photo fenton like process Fe3+/(NH4) 2S208/UV for the degradation of Di azo dye congo red using low iron concentration, Cent. Eur. J. Chem. 7 (2009) 468-477.

[43] L.G. Devi, K.S.A. Raju, S.G. Kumar, Photodegradation of methyl red by advanced and homogeneous photo-fenton's processes: a comparative study and kinetic approach, J. Environ. Monit. 11 (2009) 1397-1404.

[44] M.N. Timofeeva, S.T. Khankhasaeva, S.V. Badmaeva, A.L. Chuvilin, E.B. Burgina, A.B. Ayupov, V.N. Panchenko, A.V. Kulikova, Synthesis, characterization and catalytic application for wet oxidation of phenol of iron-containing clays, Appl. Catal. B: Environ. 59 (2005) 243-248.

[45] B. Iurascu, I. Siminiceanu, D. Vione, M.A. Vicente, A. Gil, Phenol degradation in water through a heterogeneous photo-Fenton process catalyzed by Fe-treated laponite, Water Res. 43 (2009) 1313-1322.

[46] J. Feng, X. Hu, P.L. Yue, Effect of initial solution pH on the degradation of orange II using clay-based Fe nanocomposites as heterogeneous photo-Fenton catalyst, Water Res. 40 (2006) 641-646.

[47] K. Barbusinski, J. Majewski, Discoloration of azo dye acid red 18 by fenton reagent in the presence of iron powder, Pol. J. Environ. Stud 12 (2003) $151-155$

[48] M. Neamtu, A. Yediler, I. Siminiceanu, A. Kettrup, Oxidation of commercial reactive azo dye aqueous solutions by the photo-Fenton and Fenton-like processes, J. Photochem. Photobiol. A: Chem. 161 (2003) 87-93.

[49] X. Liu, T. Zhang, Y. Zhou, L. Fang, Y. Shao, Degradation of atenolol by UV/peroxymonosulfate: kinetics, effect of operational parameters and mechanism, Chemosphere 93 (2013) 2717-2724.

[50] J.A. Khan, X. He, N.S. Shah, H.M. Khan, E. Hapeshi, D.F. Kassinos, D.D. Dionysiou, Kinetic and mechanism investigation on the photochemical 
degradation of atrazine with activated $\mathrm{H}_{2} \mathrm{O}_{2} \mathrm{~S}_{2} \mathrm{O}_{8}{ }^{2-}$ and $\mathrm{HSO}_{5}{ }^{-}$, Chem. Eng. J. 252 (2014) 393-403.

[51] H. Sun, S. Wang, Catalytic oxidation of organic pollutants in aqueous solution using sulfate radicals, Catalysis 27 (2015) 209-247.

[52] J. Flanagan, W.P. Griffith, A.C. Skapski, Nanoporous Au-TiMCM-41-An inorganic hybrid photocatalyst toward visible photooxidation of methyl orange, J. Chem. Soc. Chem. Commun. (1984) 1574-1575.

[53] I.M. Kolthoff, A.I. Medalia, H.P. Raaen, Conductivity studies in methanol, J Am. Chem. Soc. 73 (1951) 1733-1739,
[54] W. Reints, D.A. Pratt, H.G. Korth, P. Mulder, Degradation efficiencies of azo dye acid orange 7 by the interaction of heat, UV and anions with common oxidants: persulfate, peroxymonosulphate and hydrogen peroxide, J. Phys. Chem. A 104 (2000) 10713-10720.

[55] D.L. Ball, J.O. Edwards, The kinetics and mechanism of the decomposition of caro's acid, J. Am. Chem. Soc. 78 (1956) 1125-1129. 